\title{
1 Genome wide analysis of gene dosage in 24,092 individuals shows that 10,000 genes
} 2 modulate cognitive ability

Single sentence summary: CNVs' effect-sizes on intelligence are predicted using measures of

5 intolerance to haploinsufficiency and are distributed across half of the coding genes.

\section{AUTHORS:}

Guillaume Huguet $^{1,2 * *}$; Catherine Schramm ${ }^{1,2,3 * *}$; Elise Douard ${ }^{1,2}$; Tamer Petra ${ }^{1,2}$, Antoine Main $^{2,4}$; Pauline Monin ${ }^{2,5}$; Jade England ${ }^{1,2}$; Khadije Jizi $^{1,2}$; Thomas Renne ${ }^{2,6}$; Myriam Poirier ${ }^{1,2}$; Sabrina Nowak ${ }^{1,2}$; Charles-Olivier Martin ${ }^{1,2}$; Nadine Younis ${ }^{1,2}$; Inga Sophia Knoth ${ }^{1,2}$; Martineau Jean-Louis ${ }^{1,2}$; Zohra Saci ${ }^{1,2}$; Maude Auger ${ }^{1,2}$; Frédérique Tihy ${ }^{1,2}$; Géraldine Mathonnet ${ }^{1,2}$; Catalina Maftei ${ }^{1,2}$; France Léveillé ${ }^{1,2}$; David Porteous ${ }^{7,8,9}$, Gail Davies ${ }^{7}$, Paul Redmond ${ }^{7}$, Sarah E. Harris $^{7}$, W. David Hill ${ }^{7}$, Emmanuelle Lemyre ${ }^{1,2}$; Gunter Schumann ${ }^{10}$; Thomas Bourgeron ${ }^{11,12,13}$; Zdenka Pausova ${ }^{14}$; Tomas Paus ${ }^{15,16,17}$; Sherif Karama ${ }^{18,19,20}$; Sarah Lippe ${ }^{2,21}$; Ian J. Deary ${ }^{7}$; Laura Almasy $^{22}$; Aurélie Labbe ${ }^{4}$; David Glahn ${ }^{23}$; Celia M.T. Greenwood ${ }^{3,24}$; Sébastien Jacquemont ${ }^{1,2}$

** Shared first authorship

1 Department of Pediatrics, Université de Montréal, Montreal, Quebec, Canada

2 Center Hospitalier Universitaire Sainte-Justine Research Center, Montreal, Quebec, Canada

3 Lady Davis Institute for Medical Research, Jewish General Hospital, Montreal, Quebec, Canada

4 Département de Sciences de la Décision, HEC Montreal, Montreal, Quebec, Canada

5 Human Genetics and Cognitive Functions, University Paris Diderot, Sorbonne Paris Cité, Paris, France

6 Universite de Rouen Normandie, UFR des Sciences et Techniques, Rouen, France

7 Lothian Birth Cohorts group, Department of Psychology, School of Philosophy, Psychology and Language Sciences, The University of Edinburgh, Edinburgh, EH8 9JZ, UK.

8 Medical Genetics Section, Centre for Genomic \& Experimental Medicine, MRC Institute of Genetics \& Molecular Medicine, University of Edinburgh, Western General Hospital, Edinburgh, EH4 2XU, UK.

9 Generation Scotland, Centre for Genomic and Experimental Medicine, University of Edinburgh, Edinburgh, EH4 2XU, UK.

10 Institute of Psychiatry, Psychology, and Neuroscience, King's College London, London, England

11 Department of Neurosciences, Human Genetics and Cognitive Functions, Institut Pasteur, Paris, France

12 Centre National de la Recherche Scientifique Genes, Synapses and Cognition Laboratory, Institut Pasteur, Paris, France

13 Human Genetics and Cognitive Functions, University Paris Diderot, Sorbonne Paris Cité, Paris, France

14 The Hospital for Sick Children, University of Toronto, Toronto, Ontario, Canada

15 Rotman Research Institute, Baycrest, Toronto, Ontario, Canada

16 Departments of Psychology and Psychiatry, University of Toronto, Toronto, Ontario, Canada

17 Child Mind Institute, New York, New York

18 Montreal Neurological Institute, McGill University, Montreal, QC, Canada.

19 McConnell Brain Imaging Center, McGill University, Montreal, QC, Canada

20 Douglas Mental Health University Institute, Montreal, QC, Canada

21 Psychology, Université de Montréal, Montreal, QC, Canada.

22 Department of Biomedical and Health Informatics, Children's Hospital of Philadelphia, Philadelphia, PA

23 Department of Psychiatry, Yale University School of Medicine, New Haven, CT, USA; Olin Neuropsychiatric Research Center, Institute of Living, Hartford Hospital, Hartford, CT, USA.

24 Gerald Bronfman Department of Oncology, Departments of Epidemiology, Biostatistics \& Occupational Health and Human Genetics, McGill University, Montreal, Quebec, Canada

\section{Corresponding authors:}

Guillaume Huguet

Sainte Justine University Hospital

3175 chemin de la Côte-Sainte-Catherine,

Montréal, QC H3T 1C5

guillaumeaf.huguet@gmail.com

Sébastien Jacquemont

Sainte Justine University Hospital

3175 chemin de la Côte-Sainte-Catherine,

Montréal, QC H3T 1C5

sebastien.jacquemont@umontreal.ca 


\section{ABSTRACT}

61 Genomic Copy Number Variants (CNVs) are routinely identified and reported back to patients

62 with neuropsychiatric disorders, but their quantitative effects on essential traits such as cognitive

63 ability are poorly documented. We have recently shown that the effect-size of deletions on

64 cognitive ability can be statistically predicted using measures of intolerance to

65 haploinsufficiency. However, the effect-sizes of duplications remain unknown. It is also

66 unknown if the effect of multigenic CNVs are driven by a few genes intolerant to

67 haploinsufficiency or distributed across tolerant genes as well.

68 Here, we identified all CNVs >50 kilobases in 24,092 individuals from unselected and autism

69 cohorts with assessments of general intelligence. Statistical models used measures of intolerance

70 to haploinsufficiency of genes included in CNVs to predict their effect-size on intelligence.

71 Intolerant genes decrease general intelligence by 0.8 and 2.6 points of IQ when duplicated or

72 deleted, respectively. Effect-sizes showed no heterogeneity across cohorts. Validation analyses

73 demonstrated that models could predict CNV effect-sizes with $78 \%$ accuracy. Data on the

74 inheritance of 27,766 CNVs showed that deletions and duplications with the same effect-size on

75 intelligence occur de novo at the same frequency.

76 We estimated that around 10,000 intolerant and tolerant genes negatively affect intelligence when

77 deleted, and less than $2 \%$ have large effect-sizes. Genes encompassed in CNVs were not enriched

78 in any GOterms but gene regulation and brain expression were GOterms overrepresented in the

79 intolerant subgroup. Such pervasive effects on cognition may be related to emergent properties of

80 the genome not restricted to a limited number of biological pathways. 
82

83

84

85

86

87

\section{Introduction}

Copy Number Variants (CNVs) are deletions or duplications larger than 1000 base pairs. The contribution of CNVs to the etiology of intellectual disability (ID)[1-3], autism[4-6] and schizophrenia[6-8] is well established. The interpretation of CNVs in research and medical diagnostics remains essentially binary: benign or pathogenic (contributing to mental illness)[9]. The routine implementation of Chromosomal Micro-Arrays (CMAs) as a first-tier diagnostic test identifies "pathogenic" CNVs in 10 to $15 \%$ of children with neurodevelopmental disorders (NDD) [10]. A binary interpretation is however of limited use because patients present a broad spectrum of cognitive symptoms ranging from severe ID to learning disabilities. The quantitative effects of CNVs are poorly documented even for important traits such as general intelligence. It may be available for the most frequently recurrent $\mathrm{CNVs}$ but data is often collected in patients ascertained in the clinic with a bias towards severely affected individuals, leading to potentially gross overestimation of effect size. Only two studies have been conducted in unselected populations $[11,12]$ showing reduced performance on cognitive test for 24 recurrent CNVs. However, recurrent CNVs only represent a very small fraction of the total amount of ultra-rare CNVs identified in the neurodevelopmental disorder clinic as well as in the general population.

Intelligence is a major trait assessed in the developmental pediatric and psychiatric clinic. There is a significant genetic correlation between intelligence and psychiatric disorders and cognitive impairments represent a major referral criterion to the NDD clinic. The heritability of general intelligence is estimated at around 50 to $80 \%$ [13]. The heritability of variants in linkage disequilibrium with common SNPs is estimated to be around $22.7 \%$, with variants in poor linkage disequilibrium with SNPs, including rare CNVs, explaining 31.3\% of the phenotypic variation in intelligence[14]. Two recent GWAS, have identified over 200 loci associated with intelligence and education $[15,16]$, potentially implicating 1000 genes. The latter were largely non- 
108 overlapping with genes previously linked to ID [15]. Contrary to SNPs, there is no ambiguity in

109 the molecular interpretation of a fully deleted or duplicated gene, which invariably decreases or

110 increases transcription respectively. Therefore, CNVs represent a powerful tool to map the effect-

111 sizes of genes (altered by gene dosage) on human traits.

112 We have previously proposed a framework to estimate and predict the effect-size on intelligence

113 of CNVs. We showed that linear models [17] using the sum of the "probability of being loss-of-

114 function intolerant" (pLI) scores [18] of all genes included in a deletion can predict their effect-

115 size on intelligence quotient (IQ) with $75 \%$ accuracy. Our initial study was underpowered to

116 measure the effect-size of duplications. It is also unknown if only a limited number of intolerant

117 genes or a large proportion of genes within CNVs are driving effects on cognitive abilities. More

118 broadly, the number of genes modulating general intelligence remains unknown. The pLI used in

119 our earlier model, ranges from 0 to 1 but has a bimodal distribution and is essentially a

120 categorical variable classifying genes as intolerant $(>0.9)$ or tolerant $(\leq 0.9)$ to protein-loss-of-

121 function (pLoF) [18]. Continuous measures such as the LOEUF[19] (Loss-of-function

122 Observed/Expected Upper bound Fraction) were recently introduced to reflect the full spectrum

123 of intolerance to $\mathrm{pLoF}$. LOEUF range from 0 to 2 , and values below 0.35 are suggestive of

124 intolerance.

125 Our present aims were 1) to test the robustness of effect-size estimates for CNVs across

126 unselected and NDD populations, 2) to establish the effect-size on general intelligence of

127 genomic duplications, 3) to investigate the quantitative relationship between effect-size on

128 general intelligence and the frequency of de novo events, and 4) to estimate individual effect-

129 sizes for all protein-coding genes that are intolerant as well as tolerant to pLoF.

130 We identified CNVs in 24,092 individuals from five general populations, two autism cohorts and

131 one neurodevelopmental cohort. Measures of intolerance to pLoF were used as variables to

132 estimate the effect of CNVs and individual genes on general intelligence. Validation procedures 
bioRxiv preprint doi: https://doi.org/10.1101/2020.04.03.024554; this version posted October 5, 2020. The copyright holder for this preprint (which was not certified by peer review) is the author/funder. All rights reserved. No reuse allowed without permission.

133 using cognitive data on CNVs from 47 published reports and the UKBB demonstrated a near

$13480 \%$ accuracy of model estimated. We implemented an online tool to help clinicians and 135 researchers estimate the effect-size of any CNVs on general intelligence. 


\section{RESUlTS}

137 1) Deletions and duplications have a 3:1 effect-size ratio on general intelligence

138 We first sought to replicate our previous estimates for the effect-size of deletions on

139 general intelligence computed using pLI [17]. We performed a meta-analysis on 20,151

140 individuals from 5 unselected populations (Table 1, Supplementary Fig. 1) showing that the

141 deletion of one point of pLI decreases NVIQ or g-factor by 0.18 z-score (95\% CI: -0.23 to -0.14 ,

142 equivalent to 2.7 points of NVIQ, Fig. 1a, Supplementary Table 1). For duplications, we

143 performed a meta-analysis using the same unselected populations. It shows that duplicating one

144 point of pLI decreases NVIQ or g-factor by 0.04 z-score (95\% CI: -0.09 to -0.01), which is

145 equivalent to 0.75 points of IQ. Of notes, our previous study [17] was unable to estimate effect-

146 sizes of duplications on general intelligence, likely due to sample size. There was no

147 heterogeneity across cohorts. Sensitivity analyses showed that methods used for cognitive

148 assessments did not influence these results (Fig. 1, Supplementary Table 2).

2) The effect-size of CNVs on general intelligence is not influenced by ascertainment.

151 Since genomic variants with large effects on general intelligence are thought to be removed

152 from the general population as a result of negative selective pressure, this may have led to an

153 underestimation of the effect-size of CNVs in unselected populations. To examine this

154 possibility, we analyzed 3,941 individuals (Table 1, Supplementary Fig. 1) from two autism

155 cohorts, which include individuals with ID and de novo CNVs. Effect-sizes of pLI on general

156 intelligence were the same than those observed in unselected populations for deletions and

157 duplications and we did not observe any heterogeneity across cohorts (Fig. 1, Supplementary

158 Table 1). Finally, we asked if effect-sizes of pLI were the same in large CNVs rarely observed in

159 the general population or in autism cohorts. We tested $226 \mathrm{CNV}$ carriers and 325 intrafamilial

160 controls from 132 families ascertained in the clinic (Table 1). Effect-sizes of pLI on IQ were very 
161 similar with a decrease of $0.147 \mathrm{z}$-score, $95 \% \mathrm{CI}:-0.18$ to $-0.11\left(P=1.1 \times 10^{-15}\right)$ in deletions and

1620.069 z-score, $95 \%$ CI: -0.1 to $-0.04\left(P=8.7 \times 10^{-6}\right)$ in duplications (Supplementary Table 3).

164 3) Mega-analysis suggests additive effects of constraint scores on general intelligence

165 We pooled samples after adjusting for variables including cognitive test and cohorts to perform a

166 mega-analysis of 24,092 individuals carrying 13,001 deletions and 15,856 duplications

167 encompassing $36 \%$ of the coding genome (Fig. 1b, Supplementary Fig. 2a). The effect-size of

168 pLI was unchanged, decreasing general intelligence by $0.175 \mathrm{z}$-score ( $\mathrm{SE}=0.016, P=1.25 \times 10^{-28}$ )

169 and $0.054 \mathrm{z}$-score $\left(\mathrm{SE}=0.009, P=1.90 \times 10^{-9}\right)$ for deletions and duplications, respectively

170 (Supplementary Table 4). The partial $\mathrm{R}^{2}$ shows that deletions and duplications measured by pLI

171 explain respectively $0.5 \%$ and $0.1 \%$ of the total variance of intelligence in the complete dataset;

172 in line with the fact that large effect-size CNVs are rare in the general population.

173 Among 11 variables, the 2 main constraint scores (pLI and 1/LOEUF) best explained (based on

174 AIC) the variance of general intelligence (Supplementary Table 4). For the remainder of the

175 study, we transitioned to using LOEUF because it is a continuous variable (the pLI is essentially

176 binary) and is now recommended as the primary constraint score by gnomAD. Analyses using

$177 \mathrm{pLI}$ are presented in supplemental results.

178 There was no interaction between constraint scores and age or sex (Supplementary Table 5 to 8).

179 Non-linear models did not improve model fit (Supplementary Table 9 to 10), suggesting an

180 additive effect of constraint scores.

4) The effect-size of $1 / \mathrm{LOEUF}$ on intelligence is the same in recurrent neuropsychiatric

184 We show that removing 608 individuals carrying any of the 121 recurrent CNV previously 
186 on general intelligence (Supplementary Table 11). It has been posited that the deleteriousness of

187 large psychiatric CNVs may be due to interactions between genes encompassed in CNVs. We

188 therefore asked if the effect-size of 1/LOEUF is the same for CNVs encompassing small and

189 large numbers of genes. We recomputed the linear model 6 times after incrementally excluding

190 individuals with a total sum of $1 / \mathrm{LOEUF} \geq 60,40,20,10,4$ and 2.85 for deletions and

191 duplications separately. Effect-sizes remain similar whether deletions encompass $>10$ or $>60$

192 points of 1/LOEUF (Fig. 1d, Supplementary Fig. 2b).

193 5) Gene dosage of $1 \%$ of coding genes shows extreme effect-size on general intelligence.

194 Our ability to estimate large effect sizes is likely hampered by the explanatory variable

195 (1/LOEUF) used in the model because there is only a 60-fold difference between the smallest and 196 largest value. To improve model accuracy for large effect-size genes, we used a list of 256 ID-

197 genes[2, 20], previously identified with an excess of de novo mutations in NDD cohorts. We

198 identified 126 CNVs encompassing at least one ID-gene (Fig. 2).

199 We recomputed the model by integrating 4 explanatory variables: the sum of 1/LOEUF for ID

200 and non-ID-genes encompassed in deletions and duplications. The effect-size on intelligence of

201 1/LOEUF for ID-genes was 7 to 11-fold higher than the effect-size of non-ID genes which

202 remained unchanged (Supplementary Table 12, 13 and Fig. 3). The mean effect of ID-genes

203 intolerant to $\mathrm{pLoF}(\mathrm{LOEUF}<0.35)$ was a decrease of 20 points of IQ for deletions and 9 points for

204 duplications (Supplementary Table 13).

6) Model explains nearly $80 \%$ of the effect-size of CNVs.

207 As a validation procedure, we compared model estimates to published observations for 47

208 recurrent $\mathrm{CNV}$ s reported in clinical series and in the $\mathrm{UKBB}^{17}$ (Supplementary Table 14 and 15).

209 When cognitive data was available from both clinical and the UKBB ( $n=13)$, we used the mean

210 of both effect-sizes. Concordance between model estimates and previously published measures 
211 was 0.78 for all CNVs $\left(95 \%\right.$ CI, 0.66-0.86, $P=4.3 \times 10^{-11}$, Fig. 4). Accuracy was similar for

212 deletions (ICC $\left.=0.71[0.5 ; 0.84], P=1.8 \times 10^{-5}\right)$ and duplications $\left(\mathrm{ICC}=0.85[0.7 ; 0.93], P=3 \times 10^{-7}\right)$

213 as well as for small and large CNVs including trisomy 21 (Fig. 3a and 3b, Supplementary Fig. 5).

215 7) CNVs with the same impact on intelligence have the same de novo frequency.

216 Because measures of intolerance to haploinsufficiency explain equally well the effect-sizes of 217 deletions and duplications on intelligence, we investigated the relationship between effects on 218 intelligence and de novo frequency for deletions and duplications. We established inheritance for 21926,437 CNVs in 6 cohorts (Supplementary Table 16). There was a strong relationship between

220 effects on general intelligence estimated by the model and the frequency of de novo observations 221 for deletions $\left(P=1.9 \times 10^{-65}\right)$ and duplications $\left(P=4.6 \times 10^{-24}\right.$, Fig. $\left.3 \mathrm{c}\right)$.

222 Deletions and duplications with the same impact on general intelligence show similar de novo 223 frequency CNVs (Fig. 3c).

224 The concordance between the probability of occurring de novo estimated by the model (after 225 removing recurrent CNVs) and de novo frequency reported in the DECIPHER database on 31 226 recurrent CNVs was 0.81 ([0.67-0.9]; $P=8.2 \times 10^{-8}$ ) (Fig. 3d, Supplementary Table 17 and Fig. 6).

\section{8) Estimating effect-sizes of individual genes using LOEUF}

229 Since we were underpowered to perform a gene-based GWAS, we first divided all genes in 4 230 categories: highly intolerant genes (LOEUF $<0.2 ; n=980)$, moderately intolerant genes

$231(0.2 \leq$ LOEUF $<0.35 n=1,762)$, tolerant genes $(0.35 \leq$ LOEUF $<1 ; n=7,442)$ and highly tolerant

232 genes (LOEUF $\geq 1 ; n=8,267)$. This dichotomization of LOEUF values also allowed to test whether 233 the previous linear models were driven by subgroups of genes. The sum of genes in each category 234 was used as four explanatory variables to explain general intelligence in the same linear model.

235 For deletions, highly, moderately intolerant and tolerant genes showed negative effects on 
236 general intelligence (Fig. 4a, Supplementary Table 18). For duplications only moderately

237 intolerant genes showed negative effects (Supplementary Fig. 7 and Table 18).

238 We were underpowered to further subdivide these LOEUF categories, so we tested 38

239 overlapping LOEUF categories in 38 linear models. Each model used 2 explanatory variables:

240 number of genes within and outside the LOEUF category (size $=0.15$ LOEUF). For

241 haploinsufficiency, negative effects on general intelligence were observed for genes within 13

242 categories across intolerant and tolerant LOEUF values. For duplications, only 2 categories had

243 negative effects (Fig. 4a, Supplementary Fig.7 and Table 19).

9) Most biological functions affect cognition.

246 The 6,114 different genes encompassed in the CNVs of our dataset did not show any GOterm

247 enrichment except for olfactory related terms (Supplementary Tables 20). We asked if intolerant

248 (LOEUF<0.35) and tolerant genes $(0.35<$ LOEUF<1), which negatively affect IQ in the analysis

249 above were enriched in GOterms. All intolerant and tolerant genes genome-wide, were enriched

250 in 365 and 30 GOterms respectively (Fig. 4b, Supplementary Tables 21, 22). The largest group of

251 GOterms enriched in intolerant genes represented gene regulation (RNA polymerase II

252 transcription factor activity, chromatin organization; Fig. S11), cell death regulation and neuronal

253 function (dendrite and synapse). Among 23 tissues overrepresented in intolerant genes, adult

254 brain and epithelium showed the strongest enrichment (Supplementary Table 21). Top enriched

255 pathways included those in cancer, focal adhesion, Wnt signaling and MAPK (Supplementary

256 Table 21). For tolerant genes, milder enrichments included translation (tRNA) and cytoskeletal

257 structure. Among the 7 significant tissues adult brain showed the strongest enrichment (Fig. 4b,

258 Supplementary Table 22 and Fig. 12). The 2,862 intolerant and tolerant genes encompassed in the

259 CNVs of our dataset showed the same GOterm distribution observed above for the full intolerant

260 and tolerant coding genome. Genes encompassed in CNVs were therefore represented well all 
bioRxiv preprint doi: https://doi.org/10.1101/2020.04.03.024554; this version posted October 5, 2020. The copyright holder for this preprint (which was not certified by peer review) is the author/funder. All rights reserved. No reuse allowed without permission.

261 molecular functions observed for each LOEUF group at the genome-wide level (Supplementary 262 Table 23). 


\section{DISCUSSION}

265 Deletions and duplications have effect-sizes on cognitive ability that are robust across cohorts,

266 clinical diagnoses, and general intelligence assessments. The effect-size ratio on cognitive ability

267 of deletions to duplications is 3:1. The linear sum of pLI or 1/LOEUF predicted the effect-size on

268 intelligence of deletions and duplications with equal accuracy (78\%). Using categories of LOEUF

269 values, we provide the first estimates for the individual effect-sizes of protein-coding genes,

270 suggesting that half of the coding genome affects intelligence. The 2,862 genes encompassed in

271 CNVs of our dataset show the same GOterm distribution observed in the intolerant and tolerant

272 coding genome.

\section{Model validation and ascertainment biases}

275 Models show 78\% concordance with effect-size of CNVs on IQ from previous literature reports.

276 Estimates are discordant for several CNVs, which may be due to either 1) unidentified large

277 effect-size genes with unreliable LOEUF measures due to the small size of the protein coding

278 region, and 2) ascertainment bias. However, biases from clinically referred individuals can be

279 adjusted for using intrafamilial controls [21, 22]. This is confirmed by effect-sizes using the Ste

280 Justine family genetic cohort. Also, our results suggest that the effect-size of pathogenic CNVs

281 are underestimated in the $\mathrm{UKBB}$ [21] while those of small CNVs are largely overestimated in

282 clinical series. The maximum effect size measured in UKBB was only $0.4 \mathrm{z}$-score including

283 pathogenic CNVs such as 16p11.2, 2q11.2 deletions and 10q11.21-q11.23 deletion containing an

284 ID-gene (WDFY4). On the other hand, the effect size of variants such as the 16p13.11

285 duplications and 1q21.1 CNVs are likely overestimated in clinical series[23]. Therefore,

286 statistical models using a variety of disease and unselected cohorts are likely to provide the most

287 accurate estimates. Surprisingly, an autism diagnosis is not associated with a different impact of

288 CNVs on cognitive ability. A recent study characterizes this finding showing that CNVs similarly 
decrease IQ in autism and in unselected populations but are nevertheless more frequent in autism

290 than in controls with same intelligence[24].

291

\section{Individual effect-sizes of genes, and go their GOterm enrichments}

293 Our study is based on CNVs encompassing intolerant and tolerant genes with the same GOterm

294 distribution observed in those LOEUF categories genome-wide. Only one percent of coding

295 genes with the highest intolerance to pLoF has large effects on cognitive ability (20 and 9 IQ

296 points for deletions and duplications of ID genes). The rest of the intolerant genes (15\% of coding

297 genes) have moderate to mild effect-sizes. The group of all intolerant genes is enriched in many

298 GOterms including brain expression and gene regulation as previously reported for this group/2,

299 25]. Genes considered tolerant to $\mathrm{pLoF}(0.35<\mathrm{LOEUF}<1 ; 40 \%$ of coding genes $)$ impact

300 intelligence with small effect-size and are only mildly enriched in GOterms. This is reminiscent

301 of GWAS results for schizophrenia showing that most GOterms contribute to it's heritability

302 [26].

303

304 Potential clinical application

305 Models developed in this study provide a translation of gnomAD constraint scores into cognitive

306 effect-sizes. Model outputs are implemented in a prediction tool (https://cnvprediction.urca.ca/),

307 which is designed to estimate the population-average effect-size of any given CNV on general

308 intelligence, not the cognitive ability of the individual who carries the CNV. If the cognitive

309 deficits of an individual are concordant with the effect-size of the CNV they carry, one may

310 conclude that the CNV contributes substantially to those deficits. When discordant (ie. The ob-

311 served IQ drop is $\geq 15$ points (1SD) larger than the model estimate), the clinician may conclude

312 that a substantial proportion of the contribution lies in additional factors which should be

313 investigated, such as additional genetic variants and perinatal adverse events (e.g. neonatal 
314 hypoxic ischemic injury, seizure disorders etc). If IQ cannot be reliably measured (ie. $\leq 4$ years or

315 in the case of severe behavioral disorders), the cognitive impact of the CNV predicted by the

316 model may allow to anticipate the need for potential interventions. Overall, the output of this tool

317 can help interpret CNVs in the clinic, but estimates should be interpreted with caution. The model

318 can provide an estimate for the effect size on intelligence of individual genes when deleted.

319 Therefore, one may use this information to estimate the effect size on intelligence of any SNV

320 resulting in a loss of function. However, larger datasets are required to refine the estimates for

321 individual gene.

322

\section{The relationship between genetic fitness and cognitive abilities}

324 The reasons underlying the tight relationship between general intelligence and epidemiological

325 measures of intolerance to $\mathrm{pLoF}$, is unclear. This relationship is further highlighted by the fact

326 that deletions and duplications with the similar impact on intelligence occur de novo with similar

327 frequencies. Behavioral interpretations are intuitive for severe ID but do not apply for CNVs with

328 much milder effects. In other words, individuals with moderate or severe ID have limited

329 offspring due to behavioral deficits but it is unclear how small changes in intelligence may lead

330 to behavioral issues resulting in decreased fitness. Our results also suggest that genes considered

331 as "tolerant" with LOEUF < 1 affect cognitive abilities and are likely under "mild constraint".

332 Larger samples are required to better characterize the effect of this broad category of "mildly

333 intolerant" genes on cognitive ability.

336 The model relies on constraint scores (LOEUF or pLI), which are epidemiological measures of

337 genetic fitness in human populations, without any consideration of gene function [18, 19]. It is

338 likely that some genes decrease fitness (eg. genes involved in fertility) without affecting general 
intelligence. Further studies combining intolerance scores with functional categories are required

340 to investigate this question. While LOEUF was designed to measure intolerance to loss of

341 function, we used it to assess both deletions and duplications. However, our results and a recent

342 report suggest that it also measures the intolerance to increased gene expression [27]. Noise in

343 the model may be related to unreliable constraint scores computed for small genes with a limited

344 number of pLoF variants observed in the gnomAD database. Bias in the model may be

345 introduced by ID genes observed in our dataset. Indeed, they may reflect a less severe subgroup

346 and model outputs should be interpreted with caution when CNVs encompass ID-genes. Another

347 potential bias is related to the fact that models were trained on CNVs encompassing $36 \%$ of the

348 coding genome. Projections suggest that 500K individuals from an unselected population would

349 cover $78 \%$ (Fig. S8).

350 Finally, all models imply additive effects and massive datasets would be required to test for gene-

351 gene and gene-environment interactions. However, the fact that very large CNVs (such as trisomy

352 21) are accurately estimated by the model suggests that genetic interactions within large genomic

353 segments or even chromosomes cannot be readily observed. There is long standing discordance

354 between observations made at the microscopic and macroscopic level. Indeed, molecular studies

355 provide unequivocal evidence that gene-gene interactions are common but quantitative genetic

356 theory suggests that contributions from non-additive effects to phenotypic variation in the

357 population are small. Reconciling these two observations, polygenic models assume that

358 interactions are the rule rather than the exception. Interactions are, in fact, accounted for in the

359 additive models[28]. For example, LOEUF values are correlated with the number of protein-

360 protein interactions[19] and our results also show that the intolerant genes are enriched in

361 GOterms linked to "gene regulation". In other words, the level of interactions for a given gene is

362 directly related to its "individual" effect size on intelligence (ie. chromatin remodelers have a

363 very broad interaction network, low LOEUF values and high effect sizes on intelligence). 


\section{Conclusions}

366 The effect-size of deletions or duplications on intelligence can be accurately estimated with

367 additive models using constraint scores. The same relationship between gene dosage and

368 cognition apply to small benign CNVs as well as extreme CNVs such as Down syndrome. We

369 provide a map of effect-sizes at the individual gene level but to move beyond this rough outline,

370 much larger sample sizes are required. Nonetheless, these results suggest that a large proportion

$371(56 \%)$ of the coding genome covering all molecular functions influences cognitive abilities. One

372 may therefore view the genetic contribution to cognitive difference as an emergent property of

373 the entire genome not restricted to a limited number of biological pathways. 


\section{Materials and Methods}

\section{1. Cohorts}

376 We included five cohorts from the general population, two autism cohorts and one familial cohort

377 with at least one CNV-carrier child recruited for a neurodevelopmental disorder (Table1). Studies

378 for each cohort were reviewed by local institutional review boards. Parents/guardians and adult

379 participants gave written informed consent and minors gave assent.

\section{2. Measures of general intelligence}

381 General intelligence was assessed using the neurocognitive tests detailed in table 1. Measures of

382 non-verbal intelligence quotient (NVIQ) were available in five cohorts and general intelligence

383 factor (g-factor) [29] was computed in four cohorts, based on cognitive tests, primarily assessing

384 fluid non-verbal reasoning (Table1, Supplementary Fig. 1). Intelligence measures were

385 normalized using z-score transformations to render them comparable. The concordance between

386 z-scored NVIQ and g-factor available for three cohorts ranged from 60 to $77 \%$ (Supplementary

387 Table 24).

388 3. Genetic information

\section{CNV calling and filtering}

390 For all SNP array data, we called CNVs with PennCNV and QuantiSNP using previously

391 published methods [17]. For the MSSNG dataset[30], we used CNVs called on whole genome

392 sequencing by Trost et al. [31].

393 CNV filtering steps were previously published (Supplemental material). For the mega-analysis,

394 we applied an additional filtering criterion, selecting CNVs encompassing at least 10 probes for

395 all array technologies used across all cohorts. 
396 The Sainte-Justine CNV-family cohort included participants on the basis of one pathogenic CNV

397 identified in the diagnostic cytogenetic laboratory using an Agilent 180K array.

399 We annotated the CNVs using Gencode V19 (hg19) with ENSEMBL

400 (https://grch37.ensembl.org/index.html). Genes with all transcripts fully encompassed in CNVs were annotated using 12 variables present in previous article[17]. Non-coding regions were annotated with the number of expression quantitative trait loci (eQTLs) regulating genes expressed in the brain[32]. CNV scores were derived by summing all scores of genes within CNVs.[17]. Also, we used a list of 256 ID-genes[2, 20], previously identified with an excess of de-novo mutations in NDD cohorts.

406

\section{Modelling the effect of CNVs on intelligence}

409 General intelligence was adjusted within each cohort for age and sex when required $\left(Z_{\text {ad } j \text { Intell. }}\right.$;

410 see supplemental material and Supplementary Fig. 9 and 10). To estimate the effect of CNVs on 411 general intelligence, we fit the model developed by Huguet at al. [17] where the sum of pLI (or

412 any of the 10 other scores) for all genes encompassed in deletions or duplications, respectively, is

413 the variable used to predict the adjusted Z-score of general intelligence:

$$
\text { Model for deletion }\left(\mathcal{M} 1_{D E L}\right): Z_{a d j \text { intell. }} \sim \beta_{0, D E L}+\beta_{1, D E L} \times \sum_{\text {gene }} p L I
$$

415 where $\beta_{0, D E L}, \beta_{1, D E L}$ are the regression coefficients. The same model was applied to duplications.

416 First, models $\mathcal{M} 1_{D E L}$ and $\mathcal{M} 1_{D U P}$ were fitted independently and adjusted for each cohort and

417 results were used in the meta-analyses. Second, in the mega-analysis, $\mathcal{M} 1_{D E L}$ and $\mathcal{M} 1_{D U P}$ were

418 fitted after pooling all samples and adjusting on the type of cognitive measure and cohort. 
419 To take into account ID-genes that have a greater impact on intelligence, we used a model

420 including 4 predictive variables $(\mathcal{M} 2)$ :

$$
\begin{aligned}
& Z_{\text {adjintell. }} \sim \beta_{0}+ \beta_{1} \times \sum_{I D \text { gene indeletion }} \frac{1}{L O E U F}+\beta_{2} \times \sum_{I D \text { gene induplication }} \frac{1}{L O E U F}+\beta_{3} \\
& \times \sum_{n o n-I D} \text { geneindeletion } \\
& \frac{1}{L O E U F}+\beta_{4} \times \sum_{n o n-I D \text { gene induplication }} \frac{1}{L O E U F}
\end{aligned}
$$

421 where $\beta_{0}, \beta_{1}, \beta_{2}, \beta_{3}$ and $\beta_{4}$ are the regression coefficients.

422 The variance explained by deletions and duplications (measured by pLI) was computed using

423 partial $\mathrm{R}^{2}$ in the full dataset as well as the subgroup $(\mathrm{n}=14,874)$ of unrelated individuals.

424 Sensitivity analyses

425 We tested non-linearity of the effect of haploinsufficiency scores on general intelligence by using

426 polynomial regression model and by exploring a smooth function of the effect of

427 haploinsufficiency scores using a Gaussian kernel regression method (https://cran.r-

428 project.org/web/packages/KSPM/index.html) flexible enough to account for various types of

429 effects (Supplementary material).

\section{Model Validation}

431 To validate our models, we computed the concordance between model predictions and loss of IQ

432 measured for 47 recurrent CNVs obtained in previous publications (supplementary material). The

433 concordance was computed using the intraclass coefficient correlation of type $(3,1)\left(\operatorname{ICC}_{(3,1)}\right)$

434 [33].

435 Modelling the probability to be de novo

436 We performed logistic regressions to estimate the probability of a $\mathrm{CNV}$ being de novo $\left(P_{\text {de novo }}\right)$

437 as a function of the haploinsufficiency scores:

438

Model for deletions $\left(\mathcal{M} 3_{D E L}\right)$ : 


$$
\operatorname{logit}\left(P_{\text {de novo }}\right) \sim \beta_{0, D E L}+\beta_{1, D E L} \times Z_{\text {adjintell.estimated by } \mathcal{M} 2 \text { deletion. }}
$$

440 where $\beta_{0, D E L}, \beta_{1, D E L}$ are the regression coefficients. The same model was applied to duplications

$441 \quad\left(\mathcal{M} 3_{D U P}\right)$

442 For these analyses, we added two clinical populations (Decipher, decipher.sanger.ac.uk/) and the 443 cytogenetic database of Sainte-Justine Hospital, where genetic data could be compared between 444 the child and their parents, and applied the same filtering as for the previous CNV selection 445 leading to a total of 26,437 CNVs. (Supplementary Table 16). The binary outcome variable was 446 the type of transmission (1=de novo, $0=$ inherited $)$.

447 To validate these models, we computed the concordance between model estimates and percentage 448 of de novo variants computed with Decipher for 27 recurrent CNVs.

We used 4 categories of LOEUF values to estimate the effect-size of genes classified as highly intolerant (LOEUF $<0.2, \mathrm{n}=980)$, moderately intolerant $(0.2 \leq \mathrm{LOEUF}<0.35 \mathrm{n}=1,762)$, tolerant $(0.35 \leq$ LOEUF $<1, n=7,442)$, and highly tolerant to haploinsufficiency (LOEUF $\geq 1, n=8,267)$. For deletions, model 4 is as follow:

$454 \quad\left(\mathcal{M} 4_{d e l}\right)$ :

$$
\begin{aligned}
\mathrm{Z}_{\text {adj intell. } \sim \beta_{0}+} & \beta_{1} \times \sum(\text { highly intolerant genes } i)+\beta_{2} \times \sum(\text { moderately intolerant genes } i) \\
& +\beta_{3} \times \sum(\text { tolerant genes } i)+\beta_{4} \times \sum(\text { highly tolerant genes } i)
\end{aligned}
$$

455 where $\beta_{0, C V N}$ type,$\beta_{1, C V N}$ type,$\beta_{2, C V N}$ type, $\beta_{3, C V N}$ type and $\beta_{4, C V N}$ type are the regression 456 coefficients. The same model was applied for duplications.

457 To explore smaller categories of LOEUF values, we slid a window of size 0.15 LOEUF units, in 458 increments of 0.05 units thereby creating 38 categories across the range of LOEUF values. We 459 performed 38 linear models:

$460 \quad\left(\mathcal{M} 5_{\text {del }}\right)$ : 


$$
\begin{aligned}
\mathrm{Z}_{\text {adj intell. }} \sim & \left.\beta_{0, C N V \text { type }}+\beta_{1, C N V \text { type }} \times \sum \text { (genes i inside the window }\right) \\
& +\beta_{2, C N V \text { type }} \times \sum(\text { genesi outside the window })
\end{aligned}
$$

461 where $\beta_{0, C V N}$ type, $\beta_{1, C V N}$ type and $\beta_{2, C V N}$ type are the regression coefficients.

462 The same models were performed for duplications. Estimates were corrected for multiple testing

463 (38 tests) using FDR.

464 GOterms Enrichment

465 For the GOterms enrichment for the tolerant and intolerant genes with all a genome and CNVs

466 between unselected, ASD and both populations, we used DAVID release 6.8[34] (https://david-

467 d.ncifcrf.gov). We kept the defaults parameters and save only the terms with Bonferroni

468 corrected p-values <0.05. We then passed the list to REVIGO[35] (http://revigo.irb.hr/) to

469 summarize and group the redundant GO.

470

471 
1. Coe BP, Witherspoon K, Rosenfeld JA, van Bon BWM, Vulto-van Silfhout AT, Bosco P, et al. Refining analyses of copy number variation identifies specific genes associated with developmental delay. Nat Genet. 2014;46:1063-1071. 2. Coe BP, Stessman HAF, Sulovari A, Geisheker MR, Bakken TE, Lake AM, et al. Neurodevelopmental disease genes implicated by de novo mutation and copy number variation morbidity. Nat Genet. 2019;51:106-116.

\section{Wilfert AB, Sulovari A, Turner TN, Coe BP, Eichler EE. Recurrent de novo mutations in} neurodevelopmental disorders: properties and clinical implications. Genome Med. 2017;9. 4. Huguet G, Ey E, Bourgeron T. The genetic landscapes of autism spectrum disorders. Annu Rev Genomics Hum Genet. 2013;14:191-213.

5. Pinto D, Delaby E, Merico D, Barbosa M, Merikangas A, Klei L, et al. Convergence of Genes and Cellular Pathways Dysregulated in Autism Spectrum Disorders. Am J Hum Genet. 2014;94:677-694.

6. Maillard AM, Ruef A, Pizzagalli F, Migliavacca E, Hippolyte L, Adaszewski S, et al. The 16p11.2 locus modulates brain structures common to autism, schizophrenia and obesity. Mol Psychiatry. 2015;20:140-147.

7. Sakai M, Watanabe Y, Someya T, Araki K, Shibuya M, Niizato K, et al. Assessment of copy number variations in the brain genome of schizophrenia patients. Mol Cytogenet. 2015;8. 8. Szatkiewicz JP, O’Dushlaine C, Chen G, Chambert K, Moran JL, Neale BM, et al. Copy number variation in schizophrenia in Sweden. Mol Psychiatry. 2014;19:762-773.

9. Riggs ER, Andersen EF, Cherry AM, Kantarci S, Kearney H, Patel A, et al. Technical standards for the interpretation and reporting of constitutional copy-number variants: a joint consensus recommendation of the American College of Medical Genetics and Genomics (ACMG) and the Clinical Genome Resource (ClinGen). Genet Med. 2019:1-13.

10. Miller DT, Adam MP, Aradhya S, Biesecker LG, Brothman AR, Carter NP, et al. Consensus Statement: Chromosomal Microarray Is a First-Tier Clinical Diagnostic Test for Individuals with Developmental Disabilities or Congenital Anomalies. Am J Hum Genet. 2010;86:749-764.

11. Kendall KM, Bracher-Smith M, Fitzpatrick H, Lynham A, Rees E, Escott-Price V, et al. Cognitive performance and functional outcomes of carriers of pathogenic copy number variants: analysis of the UK Biobank. Br J Psychiatry. 2019;214:297-304.

\section{Stefansson H, Meyer-Lindenberg A, Steinberg S, Magnusdottir B, Morgen K,} Arnarsdottir S, et al. CNVs conferring risk of autism or schizophrenia affect cognition in controls. Nature. 2014;505:361-366.

13. Posthuma D, de Geus EJC, Boomsma DI. Perceptual Speed and IQ Are Associated Through Common Genetic Factors. Behav Genet. 2001;31:593-602.

14. Hill WD, Arslan RC, Xia C, Luciano M, Amador C, Navarro P, et al. Genomic analysis of family data reveals additional genetic effects on intelligence and personality. Mol Psychiatry. 2018;23:2347-2362.

15. Savage JE, Jansen PR, Stringer S, Watanabe K, Bryois J, de Leeuw CA, et al. Genomewide association meta-analysis in 269,867 individuals identifies new genetic and functional links to intelligence. Nat Genet. 2018;50:912-919.

16. Hill WD, Marioni RE, Maghzian O, Ritchie SJ, Hagenaars SP, McIntosh AM, et al. A combined analysis of genetically correlated traits identifies 187 loci and a role for neurogenesis and myelination in intelligence. Mol Psychiatry. 2019;24:169-181. 17. Huguet G, Schramm C, Douard E, Jiang L, Labbe A, Tihy F, et al. Measuring and Estimating the Effect Sizes of Copy Number Variants on General Intelligence in Community- 
Based Samples. JAMA Psychiatry. 2018;75:447-457. protein-coding genetic variation in 60,706 humans. Nature. 2016;536:285-291.

19. Karczewski KJ, Francioli LC, Tiao G, Cummings BB, Alföldi J, Wang Q, et al. Variation across 141,456 human exomes and genomes reveals the spectrum of loss-of-function intolerance across human protein-coding genes. BioRxiv. 2019:531210.

20. McRae JF, Clayton S, Fitzgerald TW, Kaplanis J, Prigmore E, Rajan D, et al. Prevalence and architecture of de novo mutations in developmental disorders. Nature. 2017;542:433-438.

21. D'Angelo D, Lebon S, Chen Q, Martin-Brevet S, Snyder LG, Hippolyte L, et al. Defining the Effect of the 16p11.2 Duplication on Cognition, Behavior, and Medical Comorbidities. JAMA Psychiatry. 2016;73:20-30.

22. Moreno-De-Luca A, Evans DW, Boomer KB, Hanson E, Bernier R, Goin-Kochel RP, et al. The Role of Parental Cognitive, Behavioral, and Motor Profiles in Clinical Variability in Individuals With Chromosome 16p11.2 Deletions. JAMA Psychiatry. 2015;72:119-126. 23. Bernier R, Steinman KJ, Reilly B, Wallace AS, Sherr EH, Pojman N, et al. Clinical phenotype of the recurrent 1q21.1 copy-number variant. Genet Med. 2016;18:341-349.

24. Douard E, Zeribi A, Schramm C, Tamer P, Loum MA, Nowak S, et al. Effect Sizes of Deletions and Duplications on Autism Risk Across the Genome. Am J Psychiatry. 2020:appi.ajp.2020.19080834.

25. Satterstrom FK, Kosmicki JA, Wang J, Breen MS, De Rubeis S, An J-Y, et al. LargeScale Exome Sequencing Study Implicates Both Developmental and Functional Changes in the Neurobiology of Autism. Cell. 2020;180:568-584.e23.

26. Boyle EA, Li YI, Pritchard JK. An expanded view of complex traits: from polygenic to omnigenic. Cell. 2017;169:1177-1186.

27. An open resource of structural variation for medical and population genetics | bioRxiv. https://www.biorxiv.org/content/10.1101/578674v1.full. Accessed 31 December 2019.

28. Wray NR, Wijmenga C, Sullivan PF, Yang J, Visscher PM. Common Disease Is More Complex Than Implied by the Core Gene Omnigenic Model. Cell. 2018;173:1573-1580.

29. Deary IJ. Intelligence. Annu Rev Psychol. 2011;63:453-482.

30. Yuen RKC, Merico D, Bookman M, Howe JL, Thiruvahindrapuram B, Patel RV, et al. Whole genome sequencing resource identifies 18 new candidate genes for autism spectrum disorder. Nat Neurosci. 2017;20:602-611.

31. Trost B, Walker S, Wang Z, Thiruvahindrapuram B, MacDonald JR, Sung WWL, et al. A Comprehensive Workflow for Read Depth-Based Identification of Copy-Number Variation from Whole-Genome Sequence Data. Am J Hum Genet. 2018;102:142-155.

32. Ramasamy A, Trabzuni D, Guelfi S, Varghese V, Smith C, Walker R, et al. Genetic variability in the regulation of gene expression in ten regions of the human brain. Nat Neurosci. 2014;17:1418-1428.

33. Shrout PE, Fleiss JL. Intraclass correlations: uses in assessing rater reliability. Psychol Bull. 1979;86:420-428.

34. Huang DW, Sherman BT, Lempicki RA. Systematic and integrative analysis of large gene lists using DAVID bioinformatics resources. Nat Protoc. 2009;4:44-57.

35. Supek F, Bošnjak M, Škunca N, Šmuc T. REVIGO Summarizes and Visualizes Long Lists of Gene Ontology Terms. PLOS ONE. 2011;6:e21800.

36. Schumann G, Loth E, Banaschewski T, Barbot A, Barker G, Büchel C, et al. The IMAGEN study: reinforcement-related behaviour in normal brain function and psychopathology. Mol Psychiatry. 2010;15:1128-1139.

37. Pausova Z, Paus T, Abrahamowicz M, Bernard M, Gaudet D, Leonard G, et al. Cohort Profile: The Saguenay Youth Study (SYS). Int J Epidemiol. 2017;46:e19.

38. Deary IJ, Gow AJ, Pattie A, Starr JM. Cohort Profile: The Lothian Birth Cohorts of 1921 
571 and 1936. Int J Epidemiol. 2012;41:1576-1584.

572 39. Awadalla P, Boileau C, Payette Y, Idaghdour Y, Goulet J-P, Knoppers B, et al. Cohort 573 profile of the CARTaGENE study: Quebec's population-based biobank for public health and 574 personalized genomics. Int J Epidemiol. 2013;42:1285-1299.

575 40. Smith BH, Campbell A, Linksted P, Fitzpatrick B, Jackson C, Kerr SM, et al. Cohort 576 Profile: Generation Scotland: Scottish Family Health Study (GS:SFHS). The study, its 577 participants and their potential for genetic research on health and illness. Int J Epidemiol. 578 2013;42:689-700.

579 41. Fischbach GD, Lord C. The Simons Simplex Collection: A Resource for Identification of 580 Autism Genetic Risk Factors. Neuron. 2010;68:192-195. 


\section{Acknowledgments}

586

587 Conflict of interest: The authors declare that they have no conflict of interest.

588

589 Funding/Support: This research was enabled by support provided by Calcul Quebec

590 (http://www.calculquebec.ca) and Compute Canada (http://www.computecanada.ca).

591 Sebastien Jacquemont is a recipient of a Bursary Professor fellowship of the Swiss National

592 Science Foundation, a Canada Research Chair in neurodevelopmental disorders, and a chair from

593 the Jeanne et Jean Louis Levesque Foundation. Catherine Schramm is supported by an Institute

594 for Data Valorization (IVADO) fellowship. Petra Tamer is supported by a Canadian Institute of

595 Health Research (CIHR) Scholarship Program. Guillaume Huguet is supported by the Sainte-

596 Justine Foundation, the Merit Scholarship Program for foreign students, and the Network of

597 Applied Genetic Medicine fellowships. Thomas Bourgeron is a recipient of a chair of the

598 Bettencourt-Schueler foundation. This work is supported by a grant from the Brain Canada

599 Multi-Investigator initiative and CIHR grant 159734 (Sebastien Jacquemont, Celia Greenwood,

600 Tomas Paus). The Canadian Institutes of Health Research and the Heart and Stroke Foundation of

601 Canada fund the Saguenay Youth Study (SYS). SYS was funded by the Canadian Institutes of

602 Health Research (Tomas Paus, Zdenka Pausova) and the Heart and Stroke Foundation of Canada

603 (Zdenka Pausova). Funding for the project was provided by the Wellcome Trust. This work was

604 also supported by an NIH award U01 MH119690 granted to Laura Almasy, Sebastien

605 Jacquemont and David Glahn and U01 MH119739. The authors wish to acknowledge the

606 resources of MSSNG (www.mss.ng), Autism Speaks and The Centre for Applied Genomics at

607 The Hospital for Sick Children, Toronto, Canada. We also thank the participating families for

608 their time and contributions to this database, as well as the generosity of the donors who

609 supported this program. We are grateful to all the families who participated in the Simons 
610 Variation in Individuals Project (VIP) and the Simons VIP Consortium (data from Simons VIP

611 are available through SFARI Base). We thank the coordinators and staff at the Simons VIP and

612 SCC sites. We are grateful to all of the families at the participating SSC sites and the principal

613 investigators (A. Beaudet, M.D., R. Bernier, Ph.D., J. Constantino, M.D., E. Cook, M.D., E.

614 Fombonne, M.D., D. Geschwind, M.D., Ph.D., R. Goin-Kochel, Ph.D., E. Hanson, Ph.D., D.

615 Grice, M.D., A. Klin, Ph.D., D. Ledbetter, Ph.D., C. Lord, Ph.D., C. Martin, Ph.D., D. Martin,

616 M.D., Ph.D., R. Maxim, M.D., J. Miles, M.D., Ph.D., O. Ousley, Ph.D., K. Pelphrey, Ph.D., B.

617 Peterson, M.D., J. Piggot, M.D., C. Saulnier, Ph.D., M. State, M.D., Ph.D., W. Stone, Ph.D., J.

618 Sutcliffe, Ph.D., C. Walsh, M.D., Ph.D., Z. Warren, Ph.D., and E. Wijsman, Ph.D.). We

619 appreciate obtaining access to phenotypic data on SFARI base.

620

621 Additional Contributions: Julien Buratti (Institute Pasteur), and Vincent Frouin, Ph.D.

622 (Neurospin), acquired data for IMAGEN. Manon Bernard, BSc (database architect, The Hospital

623 for Sick Children), and Helene Simard, MA, and her team of research assistants (Cégep de

624 Jonquière) acquired data for the Saguenay Youth Study. Antoine Main, M.Sc. (UHC Sainte-

625 Justine Research Center, HEC Montreal), Lionel Lemogo, M.Sc. (UHC Sainte-Justine Research

626 Center), and Claudine Passo, Pg.D. (UHC Sainte-Justine Research Center), provided

627 bioinformatical support. Maude Auger, Pg.D.; and Kristian Agbogba, B.Sc. (UHC Sainte-Justine

628 Research Center), provided website development. Dr. Paus is the Tanenbaum Chair in Population

629 Neuroscience at the Rotman Research Institute, University of Toronto, and the Dr. John and

630 Consuela Phelan Scholar at Child Mind Institute, New York.

631

632 Role of the Funder/Sponsor: The funder had no role in the design and conduct of the study;

633 collection, management, analysis, or interpretation of the data; preparation, review, or approval of 634 the manuscript; or decision to submit the manuscript for publication. 
bioRxiv preprint doi: https://doi.org/10.1101/2020.04.03.024554; this version posted October 5, 2020. The copyright holder for this preprint (which was not certified by peer review) is the author/funder. All rights reserved. No reuse allowed without permission. 
bioRxiv preprint doi: https://doi.org/10.1101/2020.04.03.024554; this version posted October 5, 2020. The copyright holder for this preprint (which was not certified by peer review) is the author/funder. All rights reserved. No reuse allowed without permission.

Tables and Figures

637

\begin{tabular}{|c|c|c|c|c|c|c|c|}
\hline Ascertainment & Cohort & Array type & $\mathbf{n}=$ & $\begin{array}{l}\text { Females, } \\
\text { n(\%) }\end{array}$ & $\begin{array}{l}\text { Age in } \\
\text { years } \\
\text { Mean } \\
\text { (SD) }\end{array}$ & $\begin{array}{l}\text { Type of intelligence } \\
\text { measures }\end{array}$ & $\begin{array}{c}\text { Z-scored } \\
\text { intelligence } \\
\text { measure } \\
\text { Mean (SD) } \\
\end{array}$ \\
\hline \multirow{8}{*}{ 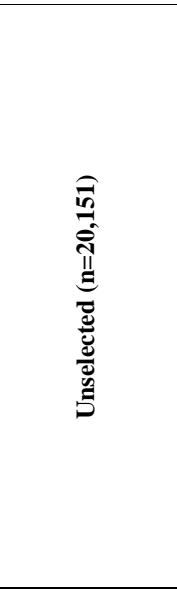 } & $\begin{array}{c}\text { IMAGEN } \\
{[36]}\end{array}$ & $\begin{array}{l}610 \mathrm{Kq} \\
660 \mathrm{Wq}\end{array}$ & 1,744 & $\begin{array}{c}891 \\
(51 \%)\end{array}$ & $\begin{array}{l}14.4 \\
(0.4)\end{array}$ & $\begin{array}{l}\text { WISC-IV (and g-factor, } \\
\text { similarities score, vocabulary } \\
\text { score, block design score, } \\
\text { matrix reasoning score) }\end{array}$ & $0.44(0.98) * * *$ \\
\hline & $\begin{array}{c}\text { SYS } \\
\text { children[37] }\end{array}$ & $\begin{array}{c}\text { 610Kq; } \\
\text { HOE-12V }\end{array}$ & 967 & $\begin{array}{c}505 \\
(52 \%)\end{array}$ & $\begin{array}{l}15.0 \\
(1.8)\end{array}$ & $\begin{array}{l}\text { WISC-III (and g-factor using } \\
63 \text { cognitive measures } \dagger \text { ) }\end{array}$ & $0.30(0.87) * * *$ \\
\hline & $\begin{array}{c}\text { SYS } \\
\text { parents[37] }\end{array}$ & HOE-12V & 602 & $\begin{array}{c}321 \\
(53 \%)\end{array}$ & $\begin{array}{l}49.5 \\
(4.9) \\
\end{array}$ & $\begin{array}{c}\text { g-factor, } 12 \text { cognitive } \\
\text { measures } \ddagger\end{array}$ & $0(1)$ \\
\hline & LBC1936[38] & $610 \mathrm{Kq}$ & 504 & $\begin{array}{c}247 \\
(49 \%)\end{array}$ & $70.0(-)^{*}$ & $\begin{array}{l}\text { Moray House Test (and g- } \\
\text { factor) }\end{array}$ & $0.05(0.96) * * *$ \\
\hline & $\begin{array}{c}\text { CaG- } \\
\text { GSA[39] } \\
\end{array}$ & GSA & 2,074 & $\begin{array}{l}1,094 \\
(53 \%) \\
\end{array}$ & $\begin{array}{l}54.3 \\
(7.6) \\
\end{array}$ & \multirow{3}{*}{$\begin{array}{c}\mathrm{g} \text {-factor, Reasoning, Memory, } \\
\text { Reaction time }\end{array}$} & $-0.02(1.03)$ \\
\hline & $\begin{array}{c}\text { CaG- } \\
\text { Omni2.5[39] }\end{array}$ & Omni2.5 & 515 & $\begin{array}{c}281 \\
(55 \%) \\
\end{array}$ & $\begin{array}{l}52.4 \\
(8.6) \\
\end{array}$ & & $-0.10(1.02)$ \\
\hline & CaG (all)[39] & $\begin{array}{c}\text { GSA; } \\
\text { Omni2.5 }\end{array}$ & 2,589 & $\begin{array}{l}1,375 \\
(53 \%) \\
\end{array}$ & $\begin{array}{l}53.9 \\
(7.8) \\
\end{array}$ & & $-0.03(1.03)$ \\
\hline & G-Scot[40] & $610 \mathrm{Kq}$ & 13,745 & $\begin{array}{l}8,101 \\
(59 \%)\end{array}$ & $\begin{array}{c}46.7 \\
(15.0)\end{array}$ & $\begin{array}{l}\text { g-factor, Logical Memory, } \\
\text { Digit Symbol, Verbal fluency, } \\
\text { Mill Hill Vocabulary }\end{array}$ & $0.00(0.99)$ \\
\hline \multirow{5}{*}{ 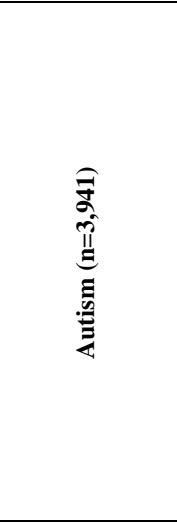 } & $\begin{array}{c}\text { SSC- } \\
\text { 1Mv1[41] }\end{array}$ & $1 \mathrm{Mv} 1$ & 332 & $44(13 \%)$ & $9.5(3.2)$ & $\begin{array}{l}\text { WISC-IV n=19; DAS-II E-Y } \\
\text { n=96; DAS-II S-A } n=179 ; \\
\text { Mullen n=12; WASI-I } n=26\end{array}$ & $-0.55(1.59)$ \\
\hline & $\begin{array}{c}\text { SSC- } \\
\text { 1Mv3[41] }\end{array}$ & $1 \mathrm{Mv} 3$ & 1,182 & $\begin{array}{c}157 \\
(13 \%)\end{array}$ & $8.8(3.5)$ & $\begin{array}{l}\text { WISC-IV n=16; DAS-II E-Y } \\
\text { n=531; DAS-II S-A n=539; } \\
\text { Mullen n=77; WASI-I n=19 }\end{array}$ & $-0.98(1.66)$ \\
\hline & $\begin{array}{c}\text { SSC- } \\
\text { Omni2.5[41] }\end{array}$ & Omni2.5 & 1.048 & $\begin{array}{c}140 \\
(13 \%)\end{array}$ & $9.2(3.7)$ & $\begin{array}{l}\text { WISC-IV n=10; DAS-II E-Y } \\
\mathrm{n}=403 ; \text { DAS-II S-A n=494; } \\
\text { Mullen n=124; WASI-I n=17 }\end{array}$ & $-1.25(1.87)$ \\
\hline & SSC (all)[41] & $\begin{array}{l}1 \mathrm{Mv} 1 \\
1 \mathrm{Mv} 3 \\
\text { Omni2.5 }\end{array}$ & 2,562 & $\begin{array}{c}341 \\
(13 \%)\end{array}$ & $\begin{array}{l}9.03 \\
(3.6)\end{array}$ & $\begin{array}{c}\text { WISC-IV } \mathrm{n}=45 ; \text { DAS-II E-Y } \\
\mathrm{n}=1,030 ; \text { DAS-II S-A } \\
\mathrm{n}=1,212 ; \text { Mullen } \mathrm{n}=213 ; \\
\text { WASI-I } \mathrm{n}=62\end{array}$ & $-1.03(1.75)$ \\
\hline & MSSNG[30] & WGS & 1,379 & $\begin{array}{c}275 \\
(20 \%)\end{array}$ & $9.2(4.4)$ & $\begin{array}{c}\text { WISC-IV n=46; WASI-II } \\
\text { n=338; Leiter } \mathrm{n}=372 ; \text { Raven } \\
\text { n=214; Standford Binet } \\
\text { n=281; WPPSI } n=128\end{array}$ & $-0.47(1.58)$ \\
\hline \multirow{4}{*}{ 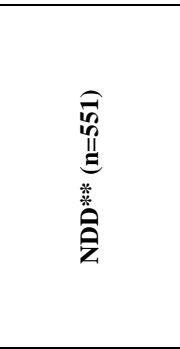 } & $\begin{array}{l}\text { Ste-Justine- } \\
\text { probands }\end{array}$ & \multirow{4}{*}{$\begin{array}{l}\text { Agilent } 180 \\
\text { K array }\end{array}$} & 132 & $52(39 \%)$ & $\begin{array}{l}7.23 \\
(5.46)\end{array}$ & $\begin{array}{c}\text { WISC-V n=36; WASI-II n=8; } \\
\text { WPPSI-IV n=38; Leiter-R } \\
\text { n=18; Mullen n=32 }\end{array}$ & $-1.31(1.02)$ \\
\hline & $\begin{array}{l}\text { Ste-Justine- } \\
\text { siblings }\end{array}$ & & 87 & $44(50 \%)$ & $\begin{array}{c}7.75 \\
(5.72)\end{array}$ & $\begin{array}{c}\text { WISC-V n=28; WASI-II } \\
\text { n=13; WPPSI-IV n=31; } \\
\text { Leiter-R n=3; Mullen n=12 }\end{array}$ & $-0.29(0.98)$ \\
\hline & $\begin{array}{l}\text { Ste-Justine- } \\
\text { parents }\end{array}$ & & 310 & $\begin{array}{c}180 \\
(58 \%)\end{array}$ & $\begin{array}{l}37.80 \\
(7.13)\end{array}$ & WASI-II & $-0.10(1.16)$ \\
\hline & $\begin{array}{c}\text { Ste-Justine- } \\
\text { other } \\
\text { members }\end{array}$ & & 22 & $12(54 \%)$ & $\begin{array}{c}43 \\
(21.27)\end{array}$ & WASI-II & $-0.04(1.32)$ \\
\hline
\end{tabular}

638

639

640 Cohorts include 24,092 individuals, including 14,874 unrelated individuals. SSC and CaG

641 cohorts were broken down into sub-samples based on array technology (Supplementary

642 methods). $† 63$ and $\ddagger 12$ cognitive measures were respectively used to compute the g-factor in

643 SYS children and parents (Supplementary methods). NDD: neurodevelopmental disorders, SYS:

644 Saguenay Youth Study, CaG: CARTaGEN, LBC: Lothian Birth Cohort, SSC: Simons Simplex 
645 Collection; $n=$ number of individuals remaining for analysis after quality control. The mean and 646 Standard Deviation (SD) for g-factor slightly deviate from 0 and 1 in some cohorts since they 647 were computed on all available data (before the exclusion of some individuals for poor quality 648 array) and summarized here only for individuals included in the analyses. *All individuals from 649 LBC1936 were assessed at 70 years old explaining the absence of SD computation. **The NDD 650 cohort was used only in the replication analysis and was not included in meta- or mega-analyses.

$651 * * *$ We displayed the Z-scores of IQ, because IQ was preferred to g-factor for all analyses, even 652 if results were similar (Supplementary Table 1 and 3). 
a

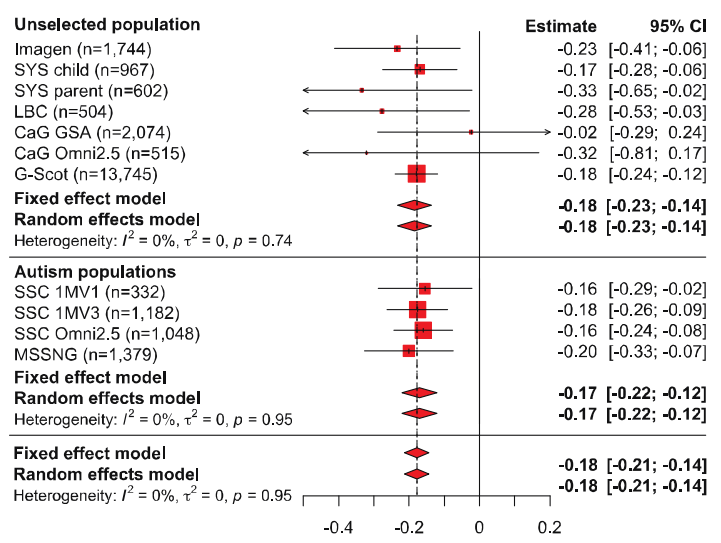

c

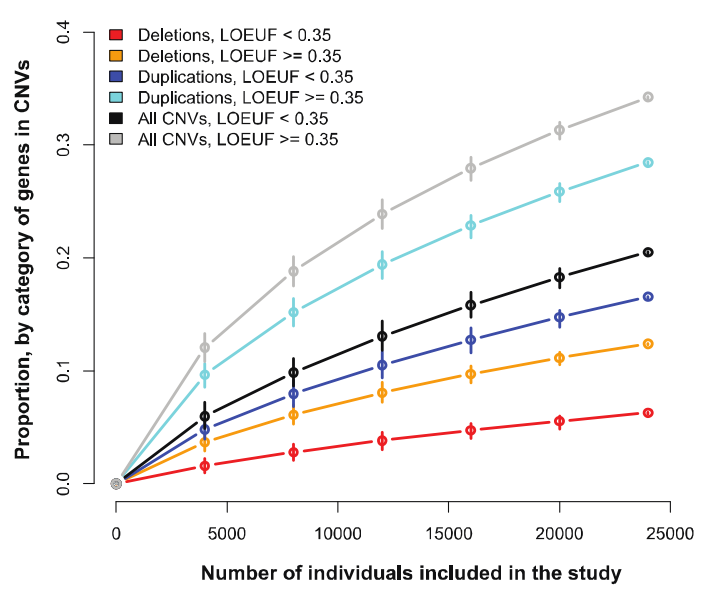

b

Unselected population

Imagen $(n=1,744)$

SYS child $(n=967)$

SYS parent $(n=602)$
LBC $(n=504)$

LaG $(n=504)$

CaG GSA $(n=2,074)$
CaG Omni2.5 $(n=515)$

G-Scot $(n=13,745)$

Fixed effect model

Random effects model
Heterogeneity: $I^{2}=62 \%, \tau^{2}=0.0023, p=0.02$

Autism populations

SSC 1MV1 $(n=332)$

SSC $1 M V 3(n=1,182)$

SSC Omni2.5 $(n=1,048)$
MSSNG $(n=1,379)$

Fixed effect model

Random effects mode

Heterogeneity: $I^{2}=0 \%, \tau^{2}=0, p=0.70$

Fixed effect model

effects model

Rat

d

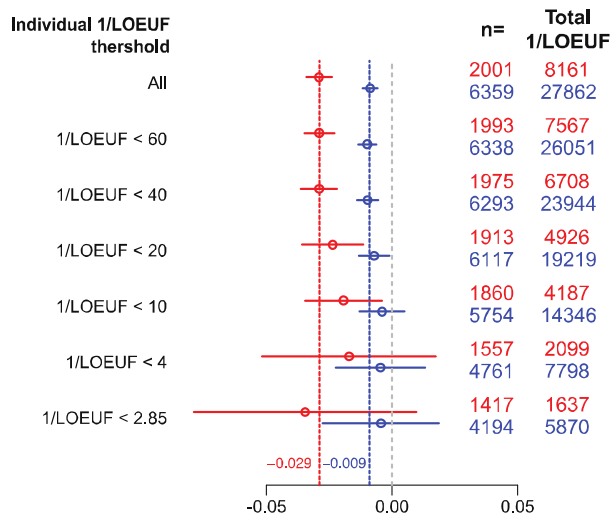

Estimate and its $95 \% \mathrm{Cl}$ associated with

$1 /$ LOEUF effect in linear mixed model

Fig. 1. Effect of intolerant score on general intelligence measured for deletions and

\section{6 duplications.}

657 Meta-analysis estimating the effect of deletions a. and duplications b., measured by sum of pLI,

658 on general intelligence (Table S1). X-axis values represent z-scores of general intelligence.

659 Deleting one point of pLI decreases the general intelligence by $0.18 \mathrm{z}$-scores (2.7 points of IQ).

660 Duplicating one point of pLI decreases the general intelligence by 0.05 z-scores $(0.75$ points of

661 IQ). The squares represent the effect-size computed for each sample. Their size negatively

662 correlated to variance. Diamonds represent the summary effect across cohorts. Their lengths

663 correspond to the $95 \%$ confidence intervals of the mean effect-size. c. Estimated proportion of

664 the coding genome within each category defined by LOEUF, encompassed in CNVs present in

665 the mega-analysis according to sample size (randomly selected within the mega-analysis). We 
bioRxiv preprint doi: https://doi.org/10.1101/2020.04.03.024554; this version posted October 5, 2020. The copyright holder for this preprint (which was not certified by peer review) is the author/funder. All rights reserved. No reuse allowed without permission.

666 observed $\mathrm{N}_{\mathrm{CNV} \text { g gene }}=6,315$ with $\mathrm{N}_{\text {Del. gene }}=2,282$ and $\left.\mathrm{N}_{\text {Dup. gene }}=5,223\right)$. d. Estimated effect of

667 1/LOEUF on general intelligence after removing individuals with a sum of 1/LOEUF larger than

$66860,40,20,10,4$ and 2.85 (2.85 corresponds to $1 / 0.35$, the cut-off for intolerance to pLoF

669 gnomAD). n: number of individuals with a total sum of 1/LOEUF $>0$.

670

671 


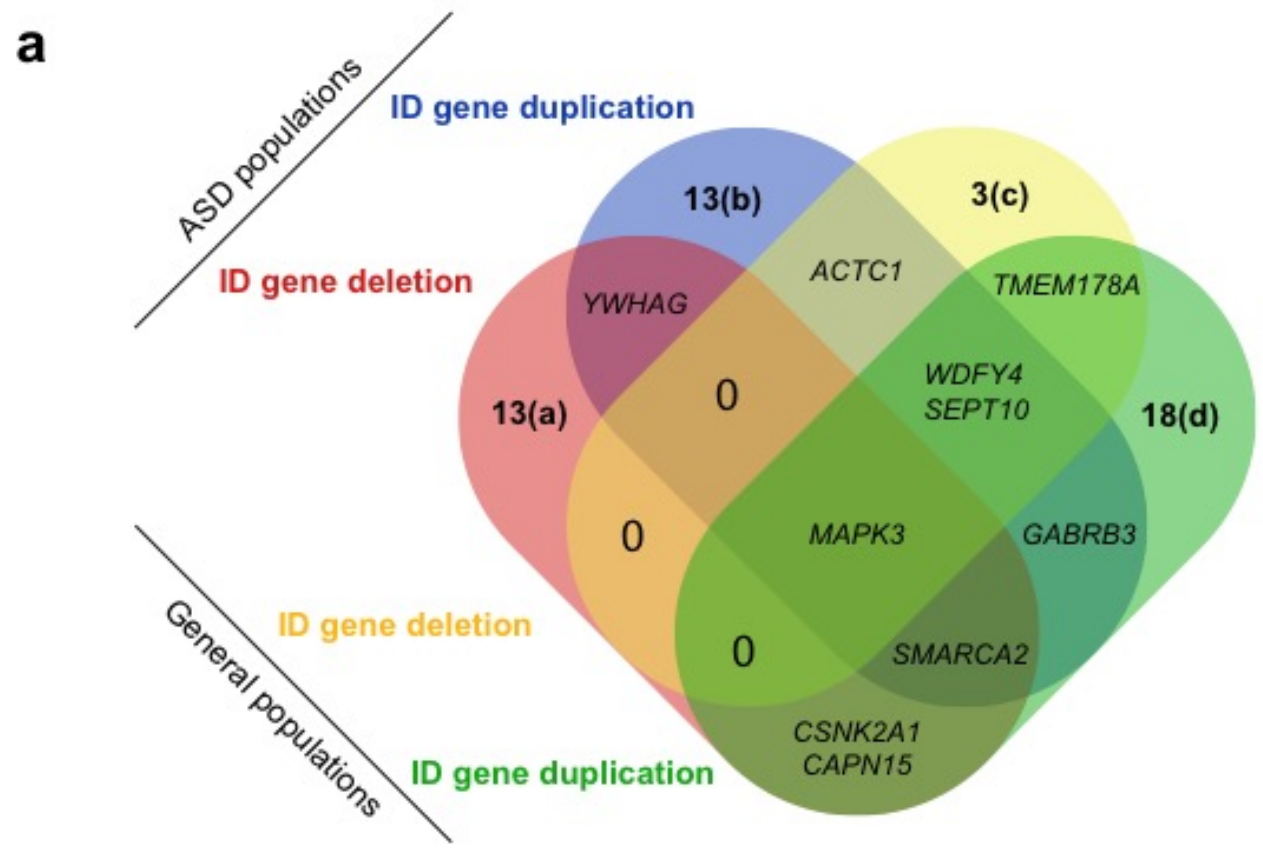

672

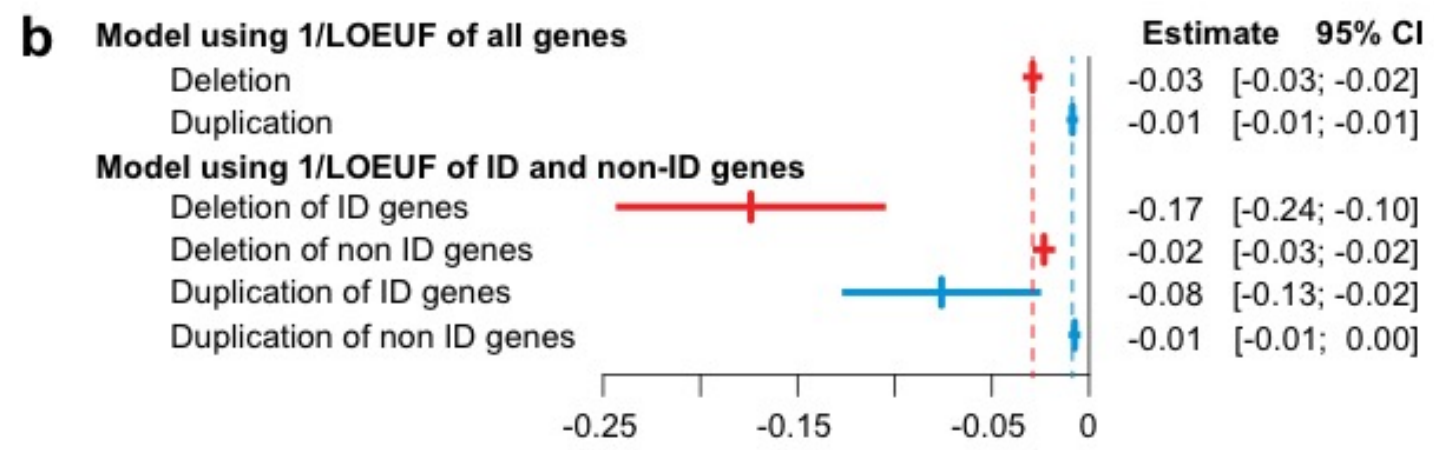

673 Fig. 2. Effect-size of intellectual disability (ID) genes on general intelligence.

674 a. Venn diagram of ID genes in ASD and in general population cohorts. We identified 66 CNVs

675 encompassing at least one ID-gene in ASD cohorts (31 deletions and 35 duplications) and 60 in

676 the general population (13 deletions and 47 duplications) (Supplementary methods). Genes were

677 previously defined as harboring an excess of de novo loss of function (bold) or missense

678 mutations in neurodevelopmental cohorts: (a) DYNC1H1, PHF21A, SHANK3, TRA2B, FOXP1,

679 SETD5, NR4A2, TCF7L2, SOX5, POU3F3, ARID1B, EBF3, HNRNPU; (b) SET, ZBTB18,

680 DLG4, CHAMP1, CNOT3, U2AF2, HIST1H2AC, DNM1, RAI1, CREBBP, HIST1H1E,

681 ASXL1, CABP7; (c) PRPF18, PPP2R1A, EEF1A2; (d) TRAF7, DEAF1, STC1, MYT1L, BRPF1, 
682 CBL, SPAST, WDR87, NFE2L3, STARD9, TCF20, KMT2C, FAM200B, KDM5B, CHD2,

683 BTF3, ITPR1, HMGXB3. b. Effect-size of 1/LOEUF on general intelligence estimated in a model

684 using two explanatory variables (sum of 1/LOEUF of deleted and duplicated genes) or 4

685 explanatory variables (sum of 1/LOEUF of ID genes and non-ID genes for deletions and

686 duplication).

687

688 

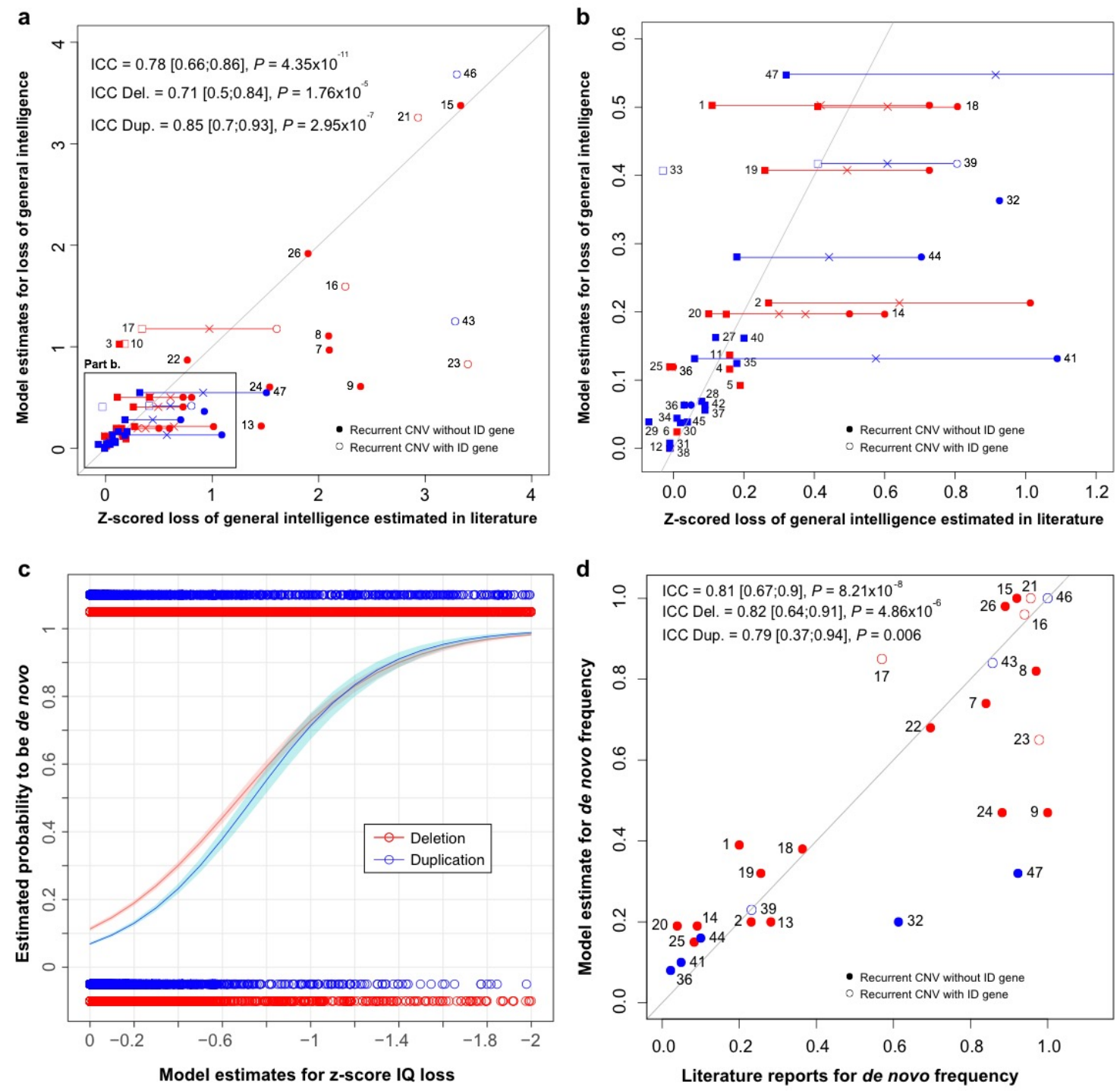

690 Fig. 3. Concordance between model predictions and published observations for CNV effects on general intelligence and for de novo frequency.

692 a. and b. Concordance between model estimates (with 1/LOEUF and ID-genes) and literature of

693 clinical data and UKBB reports for general intelligence loss observed in respectively 27 and 33

694 recurrent CNVs for a total of ascertained carriers of 47 recurrent CNVs (Supplementary Table

695 15). X-and Y-values: effect size of CNVs on z-scored general intelligence. b. Zoom of the

696 rectangle drawn in the lower left section of panel a. We represented values from clinical data by a

697 circle and those from UKBB data by a square. The cross represents the mean value of z-scored

698 IQ loss for the 13 recurrent CNVs observed both in literature and in UKBB. c. and d. The model 
699 uses 2 explanatory variables (1/LOEUF of non-ID-genes and ID-genes). c. Probability of de novo

700 estimated by our de novo model (Y-axis) according to the loss of IQ estimated by a model using

701 1/LOEUF for ID and non-ID genes as two explanatory variables (X-axis). The de novo model

702 was fitted on 13,114 deletions (red) and 13,323 duplications (blue) with available inheritance

703 information observed in DECIPHER, CHU Sainte-Justine, SSC, MSSNG, SYS and G-Scot. d.

704 Concordance between de novo frequency observed in DECIPHER (X-axis) and the probability of

705 being de novo estimated by models when excluding recurrent CNVs of the training dataset (Y-

706 axis) 1/LOEUF for ID and non-ID genes as an explanatory variable for 27 recurrent CNVs. The

707 first bisector represents the perfect concordance. Deletions are in red and duplications in blue.

708 Empty circles or square are CNVs encompassing ID-genes. ICC indicates intraclass correlation

709 coefficient $(3,1)$. Each point represents a recurrent CNV: (1) TAR Deletion; (2) 1q21.1 Deletion;

710 (3) 2q11.2 Deletion; (4) 2q13 Deletion; (5) NRXN1 Deletion; (6) 2q13 (NPHP1) Deletion; (7)

711 3q29 (DLG1) Deletion; (8) 7q11.23 (William-Beuren) Deletion; (9) 8p23.1 Deletion; (10)

712 10q11.21q11.23 Deletion; (11) 13q12.12 Deletion; (12) 13q12 (CRYL1) Deletion; (13) 15q13.3

713 (BP4-BP5) Deletion; (14) 15q11.2 Deletion; (15) 16p11.2-p12.2 Deletion; (16) 16p13.3 ATR-16

714 syndrome Deletion; (17) 16p11.2 Deletion; (18) 16p11.2 distal Deletion; (19) 16p13.11 Deletion;

715 (20) 16p12.1 Deletion; (21) 17p11.2 (Smith-Magenis) Deletion; (22) 17q12 Deletion; (23)

716 17q21.31 Deletion; (24) NF1-microdeletion syndrome Deletion; (25) 17p12 (HNPP) Deletion;

717 (26) 22q11.2 Deletion; (27) TAR Duplication; (28) 1q21.1 Duplication; (29) 2q21.1 Duplication;

718 (30) 2q13 Duplication; (31) 2q13 (NPHP1) Duplication; (32) 7q11.23 Duplication; (33)

719 10q11.21q11.23 Duplication; (34) 13q12.12 Duplication; (35) 15q11q13 (BP3-BP4) Duplication;

720 (36) 15q11.2 Duplication; (37) 15q13.3 Duplication; (38) 15q13.3 (CHRNA7) Duplication; (39)

721 16p11.2 Duplication; (40) 16p11.2 distal Duplication; (41) 16p13.11 Duplication; (42) 16p12.1

722 Duplication; (43) 17p11.2 Duplication; (44) 17q12 (HNF1B) Duplication; (45) 17p12 (CMT1A)

723 Duplication; (46) Trisomic 21 Duplication; (47) 22q11.2 Duplication. 
bioRxiv preprint doi: https://doi.org/10.1101/2020.04.03.024554; this version posted October 5, 2020. The copyright holder for this preprint (which was not certified by peer review) is the author/funder. All rights reserved. No reuse allowed without permission. 
725

726

727

728

729

730

731

732

733

734

735

736

737

738

739

740 a

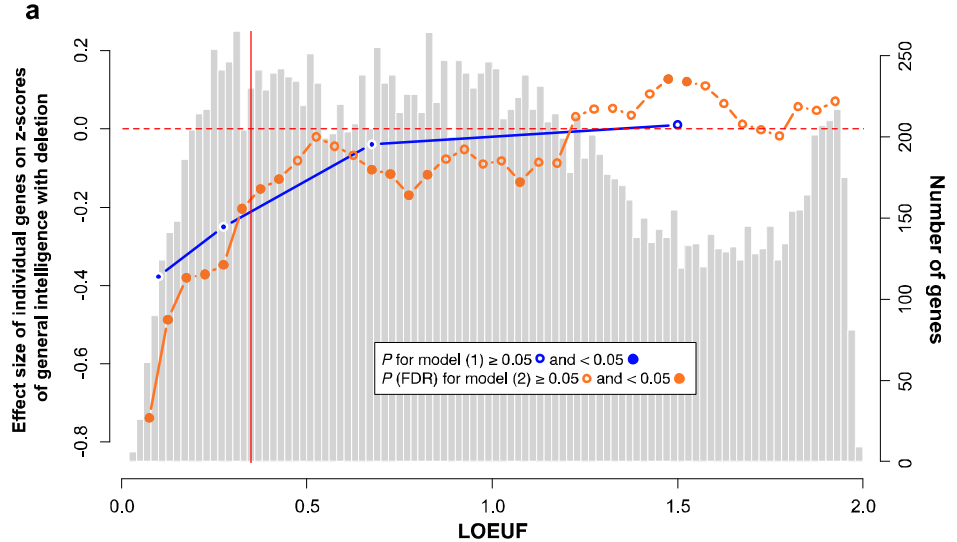

b

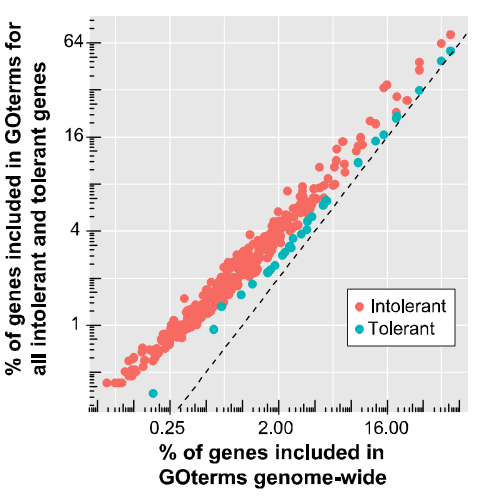

Fig. 4. Effect-size on general intelligence of individual genes encompassed in CNVs and their GOterms enrichment.

The light grey histogram represents the distribution of LOEUF values for 18,451 autosomal

genes. The blue line represents the estimates for a gene in each of the 4 categories of LOEUF

included in the model (Supplementary methods): highly intolerant genes (LOEUF $<0.2, \mathrm{n}=980$ ),

moderately intolerant genes $(0.2 \leq \mathrm{LOEUF}<0.35 \mathrm{n}=1,762)$, tolerant genes $(0.35 \leq \mathrm{LOEUF}<1$,

$\mathrm{n}=7,442)$ and genes highly tolerant to $\mathrm{pLoF}(\operatorname{LOEUF} \geq 1, \mathrm{n}=8,267)$. The orange line represents the

estimated effect-size of 37 categories of genes based on their LOEUF values (sliding

windows $=0.15$ ) in the model (Supplementary methods). Genes with a LOEUF below 0.35

(vertical red line) are considered to be intolerant to pLoF by gnomAD. Left Y-axis values: z-

scored general intelligence ( $1 \mathrm{z}$-score is equivalent to 15 points of IQ) for deletion. Right $\mathrm{Y}$-axis

values: number of genes represented in the histogram. For Fig. $6 \mathbf{b}$ each point represents a

GOterm for which enrichment was observed for all intolerant $(n=2,742)$ or tolerant genes

$(n=7,442)($ b. $)$, for all intolerant $(n=609)$ or tolerant genes $(n=2,251)$ encompassed in CNVs $(C)$

when compared to the whole coding genome (Bonferroni). b. X-axis: \% of genes included in the 
bioRxiv preprint doi: https://doi.org/10.1101/2020.04.03.024554; this version posted October 5, 2020. The copyright holder for this preprint (which was not certified by peer review) is the author/funder. All rights reserved. No reuse allowed without permission.

741 GOterm genome-wide; Y-axis: \% of genes included in the GOterm for all intolerant

$742(0<$ LOEUF $<0.35)$ and tolerant genes $(0.35 \leq$ LOEUF $<1)$. 